\title{
Supply chain resilience and key performance indicators: a systematic literature review
}

\author{
Alexandre Augusto Karla, Julio Micheluzzia, Luciana Rosa Leite ${ }^{\mathrm{a}}$, Carla Roberta Pereira ${ }^{\mathrm{a} *}$ \\ aUniversidade do Estado de Santa Catarina, Joinville, SC, Brasil \\ *carla.pereira@udesc.br
}

\begin{abstract}
Paper aims: The aim of this article is to explore the influence of non-financial key performance indicators (KPls) to create supply chain resilience (SCRes).

Originality: It theoretically identifies the influence of specific non-financial KPls when creating SCRes by monitoring them before, during and after a disruption.
\end{abstract}

Research method: A systematic literature review was conducted using 57 peer-reviewed academic papers from 2000 to 2017.

Main findings: Order and delivery lead time, on-time delivery, supplier delivery efficiency and customer satisfaction were the KPls that had a significant influence on elements of resilience.

Implications for theory and practice: Results contribute to the theory by providing knowledge in an underexplored topic, and assist managers in practice by identifying specific KPls to build resilience.

Keywords

Resilience. Key performance indicators. Systematic literature review.

How to cite this article: Karl, A. A., Micheluzzi, J., Leite, L. R., \& Pereira, C. R. (2018). Supply chain resilience and key performance indicators: a systematic literature review. Production, 28, e20180020. https://doi.org/10.1590/01036513.20180020.

Received: Mar. 16, 2018; Accepted: Sept. 5, 2018.

\section{Introduction}

According to the US Federal Emergency Management Agency (FEMA), approximately 40\% of companies that are severely affected by a disruption in the supply flow go bankrupt (Federal Emergency Management Agency, 2016). Regardless of the sector and size, supply chains face a myriad of threats in global operations, which vary from cyber risks to natural disasters. As businesses enter an era of economic, geopolitical, societal, technological and environmental uncertainty (World Economic Forum, 2017), a wide range of unforeseen and unavoidable risks may incur, which might cause minor to major impacts to companies throughout supply chains.

Recognizing that market instability directly affects supply chain operations, it is acknowledged that competition is no longer between individual companies, but rather between supply chains (Christopher, 2012). In this context, building resilience is an important factor for organizations, as well as for their supply chains (Hohenstein et al., 2015). In Operations Management, resilience is defined as a set of organizational capabilities to face immediate and unexpected changes in the environment with proactive and reactive actions so as to anticipate, adapt, respond, recover and learn from any disruptive event (Kamalahmadi \& Parast, 2016; Ali et al., 2017). Therefore, developing skills to manage organizational resources (tangible and intangible) is fundamental to achieve resilience in the supply chain, thereby achieving a competitive advantage.

Assuming that it is not possible to manage any resource that cannot be measured and that consumers are increasingly demanding, analyses and surveys regarding performance indicators have been increasing in recent 
years (Anand \& Grover, 2015). In pursuit of better operations management, managers have used Key Performance Indicators (KPls) to monitor operations as they provide internal and external visibility, and consequently help decision making (Chae, 2009).

The literature on supply chain management is wide and extensive considering the different perspectives to explore this complex concept. There is an increasing number of studies regarding resilience (Christopher \& Peck, 2004; Ponomarov \& Holcomb, 2009; Ali et al., 2017) and KPls (Chan, 2003; Cai et al., 2009; Cho et al., 2012) from a supply chain perspective. However, very few studies (Hohenstein et al., 2015) have focused on exploring the relationship between resilience and KPls and the benefits of KPls in building or improving supply chain resilience (SCRes).

In addressing this gap, this study conducts a systematic literature review (SLR) on KPls and SCRes by adopting a structured and transparent methodology such as that proposed by Tranfield et al. $(2003,2004)$ and Thomé et al. (2016). Denyer \& Tranfield (2009, p. 671) state that SLR aims to "[...] locate existing studies, to select and evaluate contributions, to analyse and synthesize data, and to report the evidence in such a way that allows reasonably clear conclusions to be reached about what it is [already] known" on a specific subject. Accordingly, this methodology has been applied in other SCM literature reviews (e.g. Colicchia \& Strozzi, 2012; Hohenstein et al., 2015; Lima et al., 2018).

The purpose of this paper is to explore the influence of non-financial key performance indicators (KPls) in the creation of supply chain resilience (SCRes). Recognizing that KPls from the supply chain perspective cover a broad scope in the management area, and that any disruption primarily has an impact on the operations of any organization, this study prioritizes exploring non-financial KPls. Moreover, we recognize that financial KPls are just as important to organizations as to the phenomenon of SCRes, however it is mostly a result of non-financial KPls (Ghalayini \& Noble, 1996). According to Nudurupati et al. (2011, p. 281), non-financial indicators "[...] act as the leading indicators for the financial performance". This study contributes to theory by raising elements of resilience and non-financial KPls from a fragmented literature, and combining them in order to explore the use of KPls in building SCRes. In practice, it can assist managers by identifying specific KPls to build resilience.

The article is structured in five sections. First, the introduction contextualizes the research problem followed by the research purpose. Second, it provides theoretical support to better understand the two main topics under study (resilience and KPls). Third, it explains the whole process of SLR in detail. The fourth section lists the KPls and elements that support resilience found in the literature to further discuss the influence between them. The last section summarizes the findings, highlighting limitations and opportunities for future studies.

\section{Theoretical overview}

This section provides theoretical support to the concepts of KPls and resilience in the context of supply chains.

\subsection{Key performance indicators}

Supply chains are commonly known as a set of organizations which are connected through different processes and activities that produce value along the pipeline in the form of products and services to attend consumers' expectations (Christopher, 2012; Asgari et al., 2016). In this context, KPls are used by organizations to manage such processes and activities (local and global). Nagyova \& Pacaiova (2009) define KPls as quantifiable (metric) aspects that reflect key factors that organizations must monitor and manage so as to achieve success. For this purpose, KPls able to portray the current scenario of an organization and its supply chain should be established, thus helping to monitor and evaluate processes (Maestrini et al., 2017).

To capture relevant metrics for processes and needs, each company generates and specifies its own KPls in terms of functional context, responsibilities and goals (Chan, 2003; Cai et al., 2009). In the supply chain context, integrating the objectives at their different levels is an important factor for the correct selection of KPls, which will provide a broader view of the business.

\subsection{Resilience in the supply chain}

The word "resilience" originally comes from materials science, referring to the ability of a system to recover its initial state after undergoing an elastic deformation without any changes in its nature (Ponomarov \& Holcomb, 2009). Therefore, due to market instability and the occurrence of environmental and manmade 
disasters, the importance of incorporating this concept was emphasized in the operations management scenario (Scavarda et al., 2015).

Admitting that almost every supply chain faces disruptions of varying severity and types (Pettit et al., 2013), being prepared for any future disruptive event allows companies to respond efficiently and effectively, and therefore become less vulnerable to disruptions (Scholten et al., 2014). Thus, resilience within organizations and throughout supply chains recognises both the ability to absorb shocks in the form of extreme events and the adaptive capability to adjust to new circumstances (Brusset \& Teller, 2017). Hence, it is recognised as a responsive capability for a firm's performance, as well as a key dimension of a firm's survival (Hohenstein et al., 2015).

However, not all risks and impacts are predictable (Christopher \& Peck, 2004; Pereira et al., 2014). Thus, if a disruption occurs in the flow of goods or information, there must be an immediate and effective response to minimize losses (Kamalahmadi \& Parast, 2017). Accordingly, to obtain adaptive capacities to better respond to disasters, companies must develop proactive and reactive actions to overcome impacts and remain competitive (Hohenstein et al., 2015). Conducting a robust systematic review, Ali et al. (2017) summarize all key concepts discussed in the supply chain resilience literature, and developed a concept mapping framework that classifies and aligns different features of resilience (phases, strategy, capability, elements, and practices). This framework will further guide the structure of the discussion between KPls and elements that support SCRes in Section 4.1.

\section{Methodology}

Considering that deductive approaches are built on the existing literature (Blaikie, 2010), and that it is a first step to achieving a major contribution to research progress (Colicchia \& Strozzi, 2012), a systematic literature review is a recently used method applied to operations management as a way of managing a growing number of studies and ensuring that no relevant research has been overlooked (Pereira et al., 2014). According to Thomé et al. (2016), SLR surpasses narrative reviews in the sense that it adopts a more rigorous and well-defined review process, which follows clear guidelines to ensure more transparency, reliability and reproducibility of findings.

Following orientations of Tranfield et al. (2003, 2004), Jesson et al. (2011), Colicchia \& Strozzi (2012) and Thomé et al. (2016), this SLR follows five main steps which are described in the protocol (Table 1).

Table 1. SLR protocol.

\begin{tabular}{|c|c|}
\hline Steps & Details \\
\hline Question formulation & - develop review questions to achieve the aim of the study \\
\hline Locating studies & $\begin{array}{l}\text { - develop search queries } \\
\text { - search on Web of Science, EBSCO and Scielo databases } \\
\text { - search in 17-year period (Jan/2000-Mar/2017) }\end{array}$ \\
\hline $\begin{array}{l}\text { Study selection and } \\
\text { evaluation }\end{array}$ & $\begin{array}{l}\text { - 1st selection: title, abstract and keywords screening; } \\
\text { - 2nd selection: introduction, conclusion and searching for the paper's content; } \\
\text { - 3rd selection: full paper's reading and assessment about four main points: quality of journal, accessibility, theoretical } \\
\text { and empirical content, and unit of analysis; }\end{array}$ \\
\hline Analysis and synthesis & $\begin{array}{l}\text { - carefully read papers; } \\
\text { - use Excel spreadsheet to code and organize the content based on what is intended to answer from the research } \\
\text { questions; } \\
\text { - content analysis of the selected papers by crossing data and observing the co-occurrence between non-financial KPls } \\
\text { and elements of resilience. }\end{array}$ \\
\hline Results presentation & $\begin{array}{l}\text { - answer the review questions based on what is known in the literature. } \\
\text { - critical analysis from the findings observing the influence of KPls from the supplier, focal company and customer } \\
\text { perspective on the creation of SCRes before, during and after the disruption. }\end{array}$ \\
\hline
\end{tabular}

\subsection{Question formulation}

Aiming to explore the influence of non-financial KPls when creating SCRes, three review questions (RQs) were addressed:

RQ1. What are the KPls used for in the context of supply chains?

RQ2. What are the elements that support supply chain resilience?

RQ3. How can non-financial KPls help create resilience in the supply chain? 
RQ1 seeks to retrieve KPls used in studies related to supply chains. At this stage, we did not limit this study to non-financial KPls so as not to overlook articles that do not classify KPls into financial and non-financial ones. RQ2 aims to identify elements responsible for creating resilience in the supply chain. Currently, Ali et al. (2017) have joined all the terms used to characterize factors that enable the development of resilience (such as principles, enablers and capabilities), and called them "elements". For this reason, we opted to use the term elements. Finally, RQ3 intends to explore the influence of non-financial KPls which can help to create SCRes and answer the aim of this study. Overall, RQ1 and RQ2 are complementary questions to RQ3.

\subsection{Locating studies}

Based on the constructs embedded into the RQs, keywords were listed to develop search queries (Table 2). Tests were made using possible search queries before defining the final ones. To do so, searches were made in $\mathrm{ABI} / \mathrm{Inform}$ and EBSCO, which are considered two of the most extensive databases in management (Khan et al., 2012; Thomé et al., 2012; Pereira et al., 2014), in addition to SCIELO which can cover searching for Brazilian studies, considering that the empirical part of this study will be conducted in Brazil.

Table 2. Search parameters.

\begin{tabular}{|c|c|c|}
\hline Constructs & Keywords & Search queries \\
\hline Supply Chain Resilience (SCRes) & $\begin{array}{l}\text { Supply chain resilience } \\
\text { Resilient supply chain } \\
\text { Resilience / resilient } \\
\text { Supply chain vulnerability } \\
\text { Vulnerability } \\
\text { Risk in supply chain } \\
\text { Risk } \\
\text { Supply chain disruption } \\
\text { Disruption }\end{array}$ & $\begin{array}{l}\text { "supply chain*” N5 (reslien* OR risk* OR } \\
\text { disruption* OR vulnerab*) }\end{array}$ \\
\hline Key Performance Indicators (KPl) & $\begin{array}{l}\text { Performance indicators } \\
\text { Performance metrics } \\
\text { Performance measures }\end{array}$ & $\begin{array}{l}\text { ("supply chain*” AND ("performance” N5 } \\
\text { (indicator* OR measure* OR metric*)) }\end{array}$ \\
\hline $\begin{array}{l}\text { Supply Chain Resilience and Key Performance } \\
\text { Indicators }\end{array}$ & $\begin{array}{l}\text { Supply chain resilience } \\
\text { Resilient supply chain } \\
\text { Resilience / resilient } \\
\text { Supply chain vulnerability } \\
\text { Vulnerability } \\
\text { Risk in supply chain } \\
\text { Risk } \\
\text { Supply chain disruption } \\
\text { Disruption } \\
\text { Performance indicators } \\
\text { Performance metrics } \\
\text { Performance measures }\end{array}$ & $\begin{array}{l}\text { (“supply chain*” N5 (reslien* OR risk* OR } \\
\text { disruption* OR vulnerab*)) AND (“supply } \\
\text { chain*” AND ("performance” N5 (indicator* OR } \\
\text { measure* OR metric*)) }\end{array}$ \\
\hline
\end{tabular}

\subsection{Study selection and evaluation}

For this search, a period of 17 years was defined (Jan/2000-Mar/2017), taking into account the beginning of publications in the area of the supply chain resilience (Pereira et al., 2014; Ali et al., 2017). From the 4,620 articles identified in the first search, 2,615 were selected after checking if the content in the titles and abstracts are related to KPls and resilience in the supply chain, and also eliminating the duplicates ( $1^{\text {st }}$ selection). The introductions and conclusions were then read to choose only articles that would certainly help answer the proposed RQs, reaching the number of 133 articles ( $2^{\text {nd }}$ selection). Finally, after reading the full articles, they were evaluated into general assessment criteria ( $3^{\text {rd }}$ selection). The criteria involved assessment about quality of journals (scholarly and peer-reviewed journals), accessibility (papers in English and Portuguese), theoretical (Resilience and KPls within supply chain context), empirical content (qualitative and quantitative), and unit of analysis (organizations and supply chain level). At the end, 57 articles were selected to finally answer the RQs. All these steps are illustrated in Figure 1. The snowballing technique was not used in this study, as the developed search queries are very specific and structured to identify articles in the literature that help answer the proposed RQs. lt, therefore, provided an adequate sample of papers (Jalali \& Wohlin, 2012). 


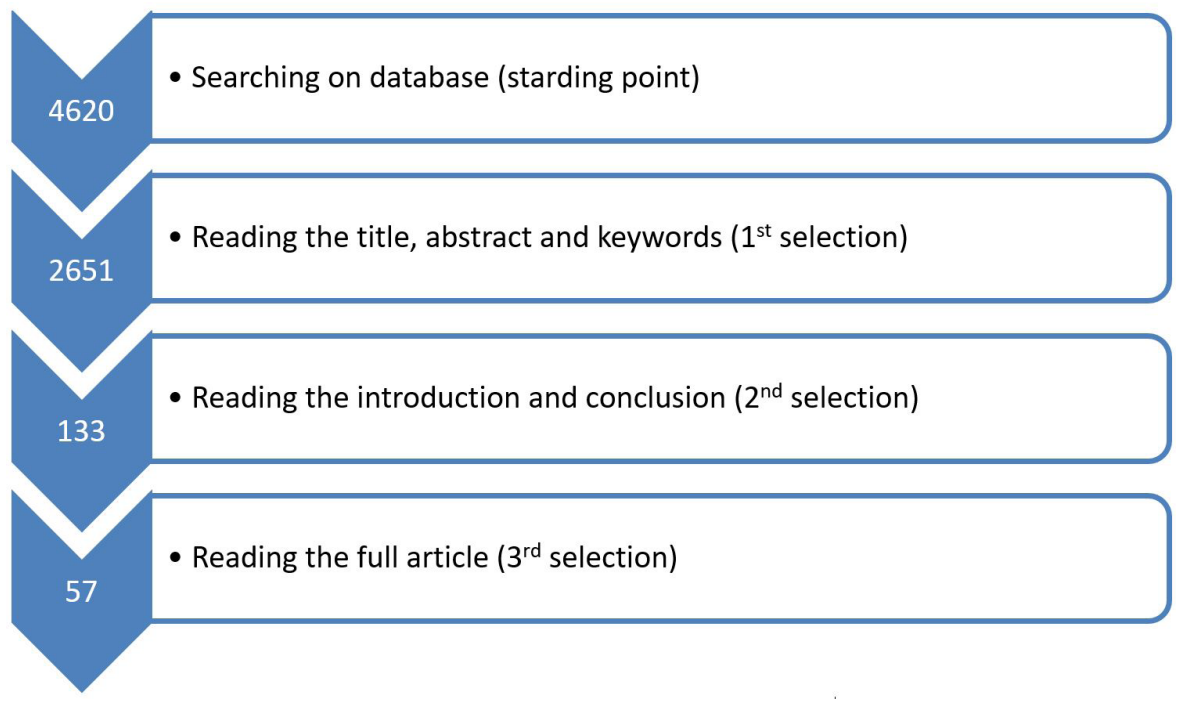

Figure 1. Systematic review process.

\subsection{Analysis and synthesis}

According to Thomé et al. (2016), a number of alternative approaches can be used to systematically analyse and synthesize the literature review. Data was analysed through the content analysis (Bardin, 2008; Seuring \& Gold, 2012), in which codes were created by reading and extracting KPls and elements of resilience from the literature. To ensure the validity of codes, the coding procedure was conducted by two researchers using MS Excel and then validated by two additional researchers. Codes were then analysed by the co-occurrence analysis technique. This analysis is a way of showing evidence of how one idea associates and co-occurs with another to interpret a relation between them (Kuckartz, 1999; Thomé et al., 2016). MS Excel supported the extraction, organization and analyses of the data.

\subsection{Presentation of results}

The final stage is presenting the findings, which answers the review questions by listing the KPls and elements of resilience found in the literature, and then discussing the influence between them. As explained in the Introduction, we focused on non-financial KPls as it is a previous stage of financial indicators, and as way to observe the performance of operations before, during and after the disruption. Along the same lines, we first classified the elements of resilience into pre, during and post-disruption by following a study conducted by Ali et al. (2017). However, we also added elements in different phases if there was co-occurrence between $\mathrm{KPl}$ and elements within a specific phase (before, during or after the disruption). Finally, a critical analysis is developed about the influence between elements and non-financial KPls, which highlights the main contribution of this paper.

\section{Findings}

By reading the 57 articles, 10 non-financial KPls and 13 elements of resilience were extracted and listed in Table 3 and Table 4, which answers the RQ1 and RQ2. From this total, only Hohenstein et al. (2015) discusses the two topics together, in which they have proposed three KPIs (customer service, market share and financial performance) that can quantify supply chain resilience. However, these KPls are still very broad and do not explore how non-financial KPls monitoring can help create SCRes. For this reason, these authors are not included in Table 3. Subsequently, RQ3 is answered by exploring the co-occurrence identified between non-financial KPls and elements that support resilience. Thus, a discussion seeks to show the influence of KPls in creating SCRes in the pre-, during- and post-disruption phases. 
Table 3. Non-financial KPls from a supply chain perspective.

\begin{tabular}{|c|c|c|c|c|c|c|c|c|c|c|c|c|c|c|c|c|c|c|c|c|c|c|c|c|}
\hline Non-financial KPls & 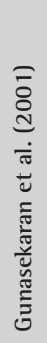 & 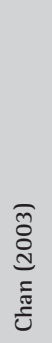 & 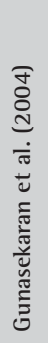 & 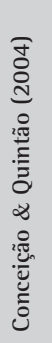 & 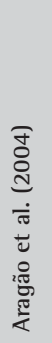 & 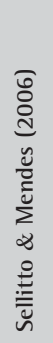 & 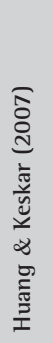 & 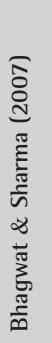 & 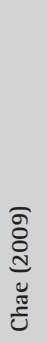 & 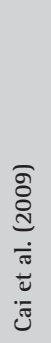 & 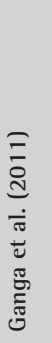 & 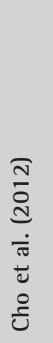 & 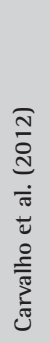 & 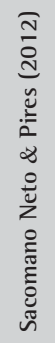 & 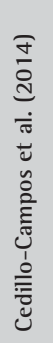 & 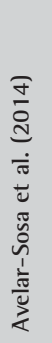 & 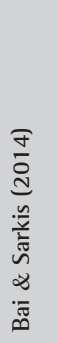 & 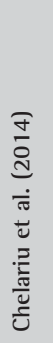 & 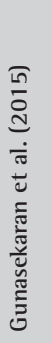 & 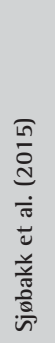 & 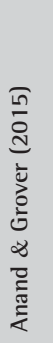 & 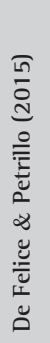 & 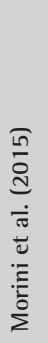 & 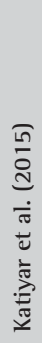 \\
\hline Capacity util & $\checkmark$ & & $\checkmark$ & & & & & $\checkmark$ & & & & $\checkmark$ & & & & & & & & & & $\checkmark$ & & $\checkmark$ \\
\hline Stock level & $\checkmark$ & $\checkmark$ & & & & & & $\checkmark$ & & & & & & & & & & & $\checkmark$ & $\checkmark$ & & & & \\
\hline Quality of delivered goods & $\checkmark$ & & $\checkmark$ & $\checkmark$ & & & & & & & $\checkmark$ & $\checkmark$ & & & & $\checkmark$ & & & & $\checkmark$ & & & & $\checkmark$ \\
\hline Order Lead Time & $\checkmark$ & $\checkmark$ & $\checkmark$ & & $\checkmark$ & & & $\checkmark$ & & $\checkmark$ & & $\checkmark$ & $\checkmark$ & $\checkmark$ & $\checkmark$ & & & & & $\checkmark$ & $\checkmark$ & $\checkmark$ & $\checkmark$ & $\checkmark$ \\
\hline Delivery Lead Time & $\checkmark$ & & $\checkmark$ & & & & & $\checkmark$ & & & & $\checkmark$ & & $\checkmark$ & & & & & & & & & & $\checkmark$ \\
\hline On-time delivery of goods & & & $\checkmark$ & $\checkmark$ & $\checkmark$ & $\checkmark$ & & & & $\checkmark$ & & & & & & $\checkmark$ & & $\checkmark$ & & & & & & $\checkmark$ \\
\hline Supplier delivery efficiency & & $\checkmark$ & $\checkmark$ & & & & $\checkmark$ & & $\checkmark$ & & & $\checkmark$ & & & & & $\checkmark$ & $\checkmark$ & & & & & & \\
\hline Supplier rejection rate & & $\checkmark$ & & & & & $\checkmark$ & & & & & & & & & & $\checkmark$ & & & & & & & \\
\hline Consumer Satisfaction & & $\checkmark$ & & $\checkmark$ & $\checkmark$ & $\checkmark$ & & & & $\checkmark$ & & $\checkmark$ & & $\checkmark$ & & $\checkmark$ & & $\checkmark$ & $\checkmark$ & & & $\checkmark$ & & $\checkmark$ \\
\hline Damage return rate & & $\checkmark$ & & & & & & & & & & & & & & & & & & & & & & $\checkmark$ \\
\hline
\end{tabular}

Table 4. The constituent elements of SCRes.

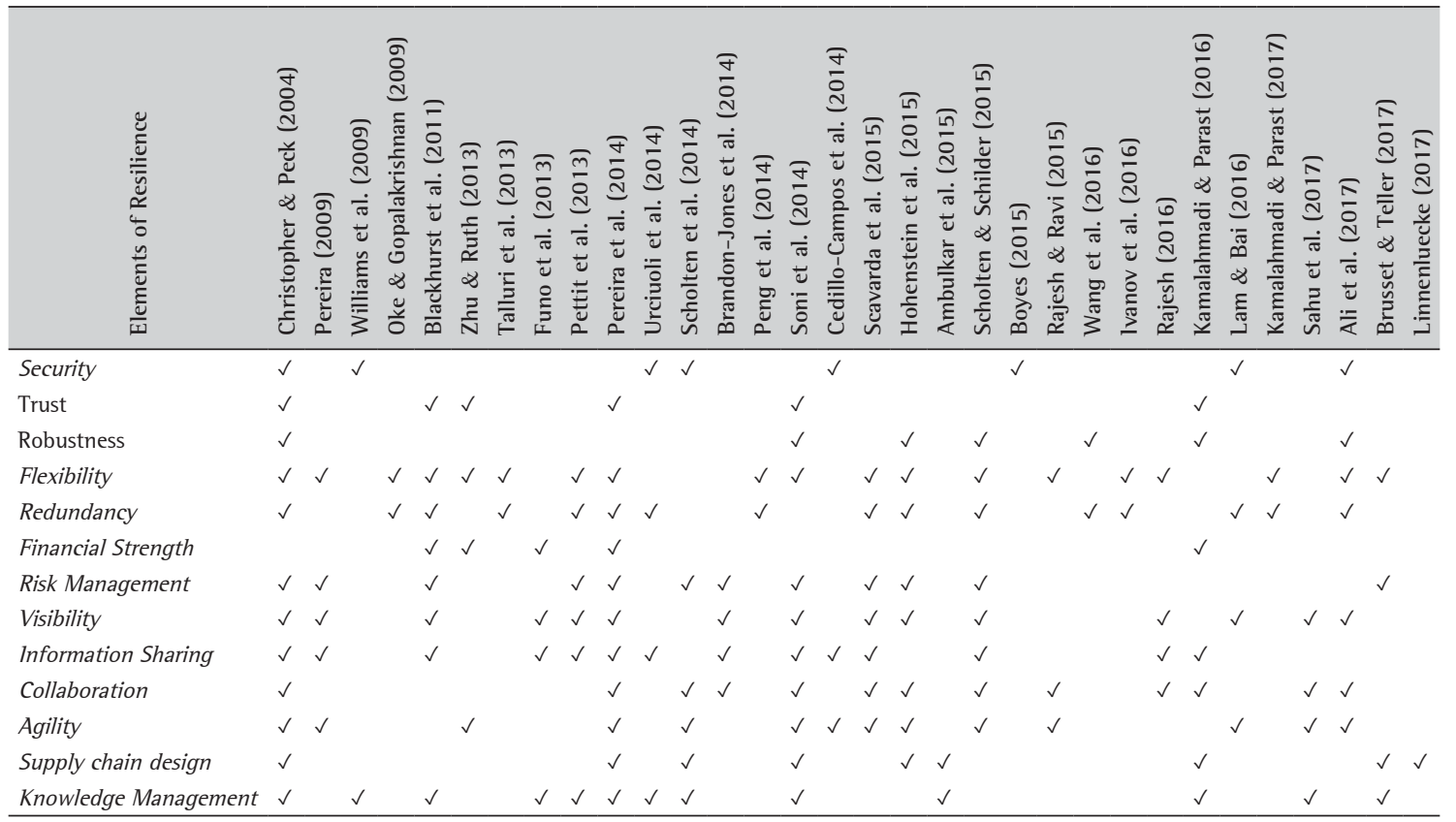

\subsection{Pre-disruption phase}

The pre-disruption phase occurs before a possible disruption in the flow of goods or service in the supply chain. The constituent elements of resilience assigned to this phase are: security, knowledge management, visibility, information sharing, trust, risk management and robustness.

\subsubsection{Security}

Security is an essential element of any supply chain and should be designed in advance to mitigate the occurrence of disruptions. Developing security in operations means protecting companies against different types of breakdowns related to the manmade disruptions - cyber-attacks or physical attacks (Scholten et al., 2014; Lam 
\& Bai, 2016). Taking this into account, security can be built and improved by creating partnerships and/or by monitoring KPls among members of the supply chain (Hohenstein et al., 2015; Ali et al., 2017).

On-time delivery is one of the KPls that presented a co-occurrence to the security element in the literature. According to Chan (2003), it measures the product delivery performance by observing the percentage of orders delivered on or before the due date. The same authors highlight that for delivery industries, customers rely on time delivery for important documents or goods transfer. Thus, monitoring this KPI can help predict future disruptions by observing the delay and promptly searching for the causes. Additionally, knowing that the result of this KPI influences the level of customer service (Katiyar et al., 2015), monitoring it can verify if customers feel secure and if they are satisfied, or if there is a need to develop practices to enhance security. Ali et al. (2017) point out some security practices, such as security culture, cyber-security, layered defenses, creating public-private partnerships (PPP) and cooperative strategies with supply chain partners.

By monitoring the on-time delivery of materials, Supplier delivery efficiency is another metric that can help develop security by dynamically identifying if a specific supplier is not meeting the companies' target (Chae, 2009). This is important because companies typically expect their deliveries to be more important than pricing (Gunasekaran et al., 2004).

\subsubsection{Knowledge management}

Understanding supply chain operations, needs and threats, as well as human and capital resources are key factors to creating a resilient supply chain (Scholten et al., 2014; Ali et al., 2017). In addition, resilience must start being built in the pre-disruption phase through practices, such as education and training (Jüttner \& Maklan, 2011) of knowledge acquired from past experiences (Christopher \& Peck, 2004; Pereira et al., 2014).

Although all the identified KPls can help build and enhance knowledge management by understanding the organization's environment, few KPls presented a clear co-occurence in the literature with this element. Capacity utilization is a common non-financial $\mathrm{KPl}$ and plays an important role in determining the performance level in a supply chain by observing how well the capacity is used in the delivery of services (Katiyar et al., 2015). According to Cho et al. (2012), by understanding the capacity utilization throughout the months, it is possible to schedule better and use the resources to increase the efficiency of operations, and consequently reduce the product's final price with a view to increasing the market share.

Furthermore, the quality of delivered goods is also a key indicator since it affects customer satisfaction (Chan, 2003). By measuring the supplier delivery efficiency, it can be gauged if it is time to search for a more reliable or qualified supplier (Cho et al., 2012). Finally, Bhagwat \& Sharma (2007) discuss a relationship among different KPls, such as capacity utilization, delivery lead time and supplier delivery efficiency. Thus, building an understanding of the pattern of KPls may help to develop knowledge management, and consequently SCRes.

\subsubsection{Visibility}

Visibility is an essential element to achieve resilience recognizing it is able to visualize conditions of inventories, demand and supply from upstream to downstream of the supply chain (Christopher \& Peck, 2004). It serves as a warning strategy that provides valuable time for companies to align their capabilities to mitigate disruptive impacts (Hohenstein et al., 2015). Due to this, Ali et al. (2017) affirm that this element is achieved and enhanced by using KPls to monitor the organizational assets (tangible and intangible).

Authors that explore visibility, such as Aragão et al. (2004), Chae (2009), Anand \& Grover (2015), Hohenstein et al. (2015) and even Ali et al. (2017), affirm that this element helps to improve the supply chain performance, considering it can estimate the accuracy of supply/demand plan and assist managers to identify the key areas of improvement - whose impacts can be seen in the operation performance and, consequently, in the financial performance of the firm. Despite the fact that these authors do not point out a specific KPI for that, they affirm that a group of KPls (financial and non-financial) can achieve an overall supply chain visibility.

\subsubsection{Information sharing}

Information sharing is also a widely recognized element for supply chain management under the effect of disruptions (Brandon-Jones et al., 2014). Sharing information in advance or in real time regarding organization assets or any events that might happen or have happened in a specific part of the supply chain (Ambulkar et al., 2015; Kamalahmadi \& Parast, 2016) can help managers to mitigate and overcome disruptions (Urciuoli et al., 2014). This is therefore the first step to achieve visibility (Ali et al., 2017). 
Cho et al. (2012) state that supply chain KPls must be linked to customer satisfaction, considering this information is needed to align customer requirement for product/service design. Additionally, monitoring stock level from suppliers and customers is also an important KPl to avoid or mitigate the bullwhip effect (Chan, 2003). To do so, information sharing about organizational assets is required among supply chain partners in order to allow upstream and downstream visibility (such as information on new project development or online order status). It can consequently help managers to make better decisions to increase the supply chain profitability (Aragão et al., 2004). To achieve this, information technology (IT) is normally used (Chae, 2009).

\subsubsection{Trust}

As previously highlighted, companies that share information among each other throughout their supply chains increase their visibility, and consequently achieve better operational results than those who work isolated (Pereira, 2009; Brusset \& Teller, 2017). For this to happen, they must trust each other, which promotes greater cooperation, conflict reduction, improved integration and decision-making under conditions of uncertainty and ambiguity (Christopher \& Peck, 2004). Therefore, trust is considered a vital element to develop resilience due to the interdependence between organizations (Soni et al., 2014).

Although trust is stated as a conceptual idea by Chan (2003), monitoring a set of KPls can help develop it. Quality of delivered goods and On-time delivered products are KPls that improve this element, considering it increases customers' trust in the company (Chan, 2003; Cho et al., 2012). Supplier delivery efficiency is another related $\mathrm{KPI}$ as it aims to measure supplier's reliability in delivering materials (Chae, 2009). Thus, any failure on the supply side may simultaneously turn into a failure in service delivery performance. To avoid such an occurrence, trustworthy relationships should be built among supply chain partners (Cho et al., 2012). Along these lines, "[...] inaccurate delivery greatly reduces the confidence of customers towards the company. It is a serious mistake that must be avoided" (Chan 2003, p. 539). For this reason, Supplier rejection rate is also a KPI that can monitor trust.

\subsubsection{Risk management}

Risk management is considered by authors (Christopher \& Peck, 2004; Hohenstein et al., 2015; Scholten \& Schilder, 2015) as part of the supply chain resilience, since many risks cannot be predicted or avoided. It can help reduce vulnerabilities through forecasting, monitoring and mitigating risks (Fernandes et al., 2011; Rajesh \& Ravi, 2015). Thus, risk management culture must extend beyond the organization's boundaries in order to understand and share the risks among partners (Christopher \& Peck, 2004).

According to Ferreira et al. (2018), there is a special characteristic of cross-company orientation in the supply chain risk management process that identifies and reduces risks not simply at the company level but rather focusing on supply chains. These authors described this process in two phases. In phase 1, the risk is analyzed through Risk ldentification, Risk Assessment, and Risk Evaluation, whilst phase 11 comprises risk control with Risk Mitigation and Risk Monitoring.

A lack of predictability and consistency in the flow of goods causes the effect of loading more inventories to avoid a lack of materials (Morini et al., 2015). Thus, monitoring the stock level can help managers to mitigate risk and reduce inventory costs. Risks can also be mitigated by observing the level of order or delivery lead time, as it is important in the context of customer service by serving as feedback to control the day-to-day operations (Chan, 2003). Supplier delivery efficiency is also seen as a KPl to monitor risks since it can monitor and observe a drop in supplier performance and consequent possible disruption in the flow of goods (Gunasekaran et al., 2004; Cho et al., 2012). Analyzing data from these KPls can orientate managers to minimize the risk of supply disruptions (Chan, 2003).

\subsubsection{Robustness}

Robustness is characterized by Brandon-Jones et al. (2014) as the ability of the supply chain to support impacts arising from different disruptions or maintaining continuity of the process. Moreover, Scholten et al. (2014) assert that developing robustness helps companies to sustain the operations' performance by being resistance to any major disruption.

In this context, Hohenstein et al. (2015, p. 108) affirm that 
[...] to assess the level of readiness, the analysis indicated that robustness measures (e.g., inventory holding, redundancy, multiple sourcing) foster SCRes proactively to absorb sudden shocks and reduce the potential disruption impact on performance.

Therefore, monitoring the stock level is a way to prepare the company for major and unavoidable breaks.

\subsection{During-disruption phase}

When the disruption has happened, KPls can also be useful in monitoring the impacts and taking actions. The constituent elements of resilience in this phase are: visibility, information sharing, collaboration, agility, flexibility, redundancy and supply chain design. Due to the fact that visibility and information sharing have already been discussed in the pre-disruption phase, their definition will not be mentioned in this subsection.

\subsubsection{Visibility}

Knowing that even a simple supply chain consists of suppliers, manufacturers, distributors and customers, any requirement or change in the customer's order can take a long time to go through from one end to another. In this case, information might be distorted on the way and many mistakes can occur (Christopher \& Peck, 2004). During a disruption, information must flow efficiently so as the supply chain has a great chance to succeed. Therefore, visibility for a supply chain is important for accurate and fast delivery of information (Chan, 2003). Equally as in the pre-disruption phase, no co-occurrence has been found between a specific KPl and this element; nevertheless, it was affirmed in the literature that the management of a set of KPls can certainly generate visibility (Aragão et al., 2004; Chae, 2009; Anand \& Grover, 2015; Hohenstein et al., 2015; Ali et al., 2017).

\subsubsection{Information sharing}

According to Bhagwat \& Sharma (2007), stock leveland delivery lead times are important KPls to be measured and monitored. Being sure about the available stock and hence knowing the average time for deliveries, managers can better observe if the impacts from the disruption are increasing or decreasing. By doing this, they keep up to date with the impacts, consequences and supply chain partners' actions (Gunasekaran et al., 2001; Cho et al., 2012). Fast service and responding properly to customers' queries are crucial for keeping customers satisfied (Katiyar et al., 2015), and hence develop SCRes.

\subsubsection{Collaboration}

According to Ali et al. (2017, p. 27), “[...] collaboration is the ability to respond to supply chain disruptions with partners through collaborative planning and information- and knowledge-sharing to coordinate the immediate response". Collaboration among all members of the supply chain is required especially in times of disruption (Scholten \& Schilder, 2015). Additionally, Christopher \& Peck (2004) had already stated that a high level of collaboration in supply chains can significantly help reduce risk, as the greatest challenge for managers is to create conditions in which collaborative work becomes possible.

Quality of delivered goods and Supplier delivery efficiency are both KPls that have clear co-occurrence in the literature. Chan (2003) affirms that collaboration is needed to increase the quality of delivered goods as customer satisfaction depends on the result of this KPI. It can also be observed in Cho et al. $(2012$, p. 805) that "[...] suppliers contribute directly to the production of services and are usually in direct contact with customers". The same authors state that any mistake on the supply side might be replicated to the demand side. Hence supplier delivery efficiency is a KPI that should be monitored daily, especially during the disruption time when the rate of this indicator normally drops. Damage return rate, as well as supplier rejection rate are additional $\mathrm{KPls}$ that require collaboration between supply chain partners in order to reduce problems and improve its operational results for all of them (Katiyar et al., 2015).

\subsubsection{Agility}

Agility refers to the company's ability to respond rapidly to changes, which helps reduce the impacts of disruptions and enhances the response time (Ali et al., 2017). It is recommended that managers segment markets (based on volume, product variety and demand uncertainty) to reduce costs and increase responsiveness to mitigate supply chain risks (Hohenstein et al., 2015). 
Regarding this element, Bhagwat \& Sharma (2007, p. 48) affirm that "[...] capacity utilization directly affects the speed of response to customers' demands". This is particularly important in times of disruption, considering that there might be available capacity to surplus the urgent requirements. The same authors also state that it helps to gain flexibility and deliverability. Likewise, monitoring the stock level is a fundamental action during disruptions so as to guarantee that available stock will certainly cover urgent orders (Chan, 2003; Bhagwat \& Sharma, 2007).

According to Gunasekaran et al. (2001) and Chan (2003), a reduction in the order lead time leads to a reduction in the supply chain response time. In other words, it decreases the lead time from end to end of the pipeline and increases customer satisfaction (Morini et al., 2015). This is also true for delivery lead time (Katiyar et al., 2015). Thus, measuring these KPls can help managers act during disruption, and consequently in creating SCRes.

According to Chan (2003, p. 538), “[...] time is a very important element anywhere in the world". Thus, if the organization, as well as its supply chain, can deliver a product much faster than its competitors, customer satisfaction will certainly increase. This is especially true in times of disruption (Scholten et al., 2014).

\subsubsection{Flexibility}

Flexibility is the organization's ability to meet a growing variety of customer expectations without excessive costs, organizational disruptions or performance losses (Pettit et al., 2013). This element facilitates coordination processes and allows organizations to cope with high levels of uncertainties (Talluri et al., 2013). Thus, a resilient supply chain can deal with unexpected disruptions and disasters by reaching a relevant level of flexibility (Sahu et al., 2017).

Katiyar et al. (2015) correlates and analyses different KPls. As a result, these authors highlighted that monitoring capacity utilization, on-time delivery of goods and delivery lead time will help managers to flexibilize operations to rapidly attend customers' needs. Order lead time and delivery lead time also presented an interesting co-occurence for flexibility in Chan (2003)'s research. They stated that once a customer gives an order to collect a package, a collector has to draw up a flexible route to collect the package within the established lead time.

\subsubsection{Redundancy}

One alternative to overcome disruptions is to create redundancy of resources in the supply chain. This element is characterized by additional capacity (production, transportation, inventory and storage facility) that can rapidly replace losses during unexpected events (Christopher \& Peck, 2004). Although additional stock is an opposite way of thinking to the Lean Management System, in which limited or no inventory is promoted (Kamalahmadi \& Parast, 2016), the redundancy may give time to managers to come up with an effective solution (Pereira et al., 2014).

During turbulent periods, holding extra resources is a key strategy for companies to overcome critical and scarce situations caused by supply disruptions (Christopher \& Peck, 2004). Stock level is a KPI that helps managers to visualize how long the organization can maintain its operations in case a supply breakdown occurs. In this regard, Chan (2003, p. 538) clarifies that

[...] safety stock is necessary, as there may be a sudden increase in orders or other interruptions can occur (which should be kept as low as possible) during manufacturing. [However], it is important for the manager to determine the optimum resources necessary for every order.

Along these lines, Morini et al. (2015) also highlight that redundancy can generate agility, because customer orders can be placed immediately by means of available stock. It therefore reduces order lead time and hence increases customer satisfaction (Gunasekaran et al., 2015).

\subsubsection{Supply chain design}

Re-designing the supply chain is one of the elements that makes supply chains more robust, secure and agile by focusing on location strategies (Christopher \& Peck, 2004). If this element is performed in real time, it is possible to mitigate risks and consequences of supply chain disruptions or even to avoid looming disruptive events (Pereira et al., 2014). Therefore, supply chains are mainly designed to achieve two objectives: cost optimization and customer satisfaction (Kamalahmadi \& Parast, 2016).

As stated, security is an essential element of any supply chain and should be designed to mitigate the occurrence of disruptions. To build security, re-designing the supply chain is also required. Thus, by monitoring 
the quality of delivered goods, failures can be identified from one source and then actions can be taken to reallocate to another source (Chan, 2003; Pereira et al., 2014).

According to Chan (2003), if the product is available from the warehouse, the order lead time can considerably decrease. However, if the slack of inventory is not possible (as discussed in the redundancy element), order lead time depends very much on the distribution network designed by the focal company. Therefore, during disruptions, this $\mathrm{KPl}$ can be kept as previously established if the supply chain is adaptable (Christopher \& Peck, 2004; Ali et al., 2017).

\subsection{Post-disruption phase}

After disruptions, KPls should also be used to measure and monitor the recovery and lessons learned (Hohenstein et al., 2015; Ali et al., 2017). The constituent elements of resilience in this phase are: knowledge management, information sharing, visibility, and collaboration.

\subsubsection{Knowledge management}

Knowledge management can be increased through optimization and control of the supplier delivery efficiency, considering that after disruptions, the identification of the supplier efficiency rate can help managers to make decisions about keeping the source or searching for another (Pereira et al., 2014; lvanov et al., 2016). This rationale is also true for the quality of delivered goods (Lam \& Bai, 2016).

According to Christopher \& Peck (2004, p. 2), supply chain resilience is defined as "[...] the ability of the system to return to its original state or move to a new and more desirable state, after being disturbed". In this regard, monitoring the order or delivery lead time and on-time delivery of goods are ways to understand the supply chain behavior pre- and post-disruption, and thus develop strategies to achieve the more desirable state. Finally, Sacomano Neto \& Pires (2012) explain the customer satisfaction measurement in the automotive sector, in which through after-sales monitoring, the assembler industry performs a diagnosis to check the critical points to be improved for future unexpected events.

\subsubsection{Information sharing and visibility}

Following the same rationale in the prior phases, information sharing and visibility are the basis for achieving knowledge management (Pereira et al., 2014; Ali et al., 2017). Therefore, the discussed KPls (stock level, delivery lead time and customer satisfaction) are also beneficial (Gunasekaran et al., 2001; Cho et al., 2012; Katiyar et al., 2015) in the post-disruption phase.

\subsubsection{Collaboration}

To achieve a higher level of collaboration, order/delivery lead time and on-time delivery of goods should be controlled and optimized (Chan, 2003), considering that a collaborative supply chain is based on deadlines, including production and delivery times at all links in the chain (Scholten et al., 2014). Additionally, the supplier rejection rate can also be improved by increasing collaboration between supply chain members (Bhagwat \& Sharma, 2007; Huang \& Keskar, 2007).

\subsection{Critical analysis of the findings}

Table 5 summarizes the prior discussion. In addition to the classification of elements into pre-, during, and post-disruption, KPls were also organized into performance indicators related to focal company, supplier and customer. In doing so, key characteristics can be observed that ensure KPls have a positive influence when creating resilience throughout the main members of a supply chain.

From the focal company perspective, it is noted that all non-financial KPls identified in this study can influence the creation of SCRes in the three phases of disruption. Thus, companies can make use of them to monitor operations and manage resources so as to overcome any disruptive event that might happen. This, therefore, leads to actions to add to resilience within the organization or throughout the supply chain. Furthermore, delivery lead time, order lead time and stock level showed great connection to the elements of resilience (more than five co-occurrence), which make them relevant to the SCRes phenomenon. Moreover, there is an intense connection between these KPls to the during and post-disruption phases. This occurs because in the moment 
Table 5. Summary of non-financial KPls and elements of resilience.

\begin{tabular}{|c|c|c|c|c|c|c|c|c|c|c|c|}
\hline & & \multicolumn{6}{|c|}{ Focal Company } & \multicolumn{2}{|c|}{ Supplier } & \multicolumn{2}{|c|}{ Customer } \\
\hline & & 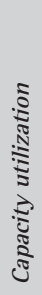 & 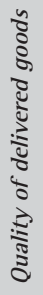 & 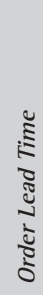 & 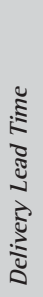 & 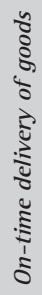 & $\frac{\bar{\Xi}}{\frac{\grave{d}}{\tilde{n}}}$ & 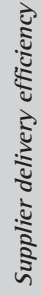 & 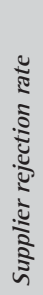 & 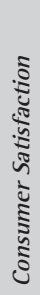 & 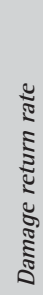 \\
\hline \multirow{7}{*}{ 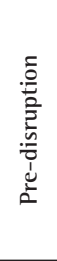 } & Security & & & & & $\checkmark$ & & $\sqrt{ }$ & & $\checkmark$ & \\
\hline & Knowledge Management & $\checkmark$ & $\checkmark$ & & $\checkmark$ & & & $\checkmark$ & & $\checkmark$ & \\
\hline & Visibility & & & & & & & & & & \\
\hline & Information Sharing & & & & & & $\checkmark$ & & & $\checkmark$ & \\
\hline & Trust & & $\checkmark$ & & & $\checkmark$ & & $\checkmark$ & $\checkmark$ & & \\
\hline & Risk Management & & & $\checkmark$ & $\checkmark$ & & $\checkmark$ & $\checkmark$ & & & \\
\hline & Robustness & & & & & & $\checkmark$ & & & & \\
\hline \multirow{7}{*}{ 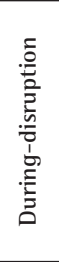 } & Visibility & & & & & & & & & & \\
\hline & Information Sharing & & & & $\checkmark$ & & $\checkmark$ & & & $\checkmark$ & \\
\hline & Collaboration & & $\checkmark$ & & & & & $\checkmark$ & & $\checkmark$ & $\checkmark$ \\
\hline & Agility & $\checkmark$ & & $\checkmark$ & $\checkmark$ & & $\checkmark$ & & & $\checkmark$ & \\
\hline & Flexibility & $\checkmark$ & & $\checkmark$ & $\checkmark$ & $\checkmark$ & & & & & \\
\hline & Redundancy & & & $\checkmark$ & & & $\checkmark$ & & & $\checkmark$ & \\
\hline & Supply chain design & & $\checkmark$ & $\checkmark$ & & & & & & $\checkmark$ & \\
\hline \multirow{4}{*}{ 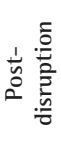 } & Knowledge Management & & $\checkmark$ & $\checkmark$ & $\checkmark$ & $\checkmark$ & & $\checkmark$ & & $\checkmark$ & \\
\hline & Visibility & & & & & & & & & & \\
\hline & Information Sharing & & & & $\checkmark$ & & $\checkmark$ & & & $\checkmark$ & \\
\hline & Collaboration & & & $\checkmark$ & $\checkmark$ & $\checkmark$ & & & $\checkmark$ & & \\
\hline
\end{tabular}

of a disruption, companies normally drive their attention to attend orders and meet deadlines, and one of the common strategies to achieve this is through stock (Fernandes et al., 2011; Pereira et al., 2014).

From the supplier's perspective, KPls showed a considerable influence on the pre-disruption phase, but not many on the during and post-disruption phases, which are critical phases in resilience to maintain the operations and build a strong relationship between buyers and suppliers. With respect to the customer perspective, customer satisfaction showed co-occurrence with 10 elements, while damage return rate co-occurred only with the collaboration element. Likewise the analysis of the three KPls above, this highlights the interest of companies in monitoring the customer's satisfaction, as it is the key for their success and survival. This analysis is especially true in the during-phase disruption, while companies have to maintain their operations to fulfill customers' requirement. Nevertheless, authors (Chan, 2003; Cho et al., 2012; Sacomano Neto \& Pires, 2012) emphasize that customer satisfaction is a result of the management of other KPls. Due to this, customer satisfaction is the KPI that showed more connections to the elements of resilience.

Overall, Table 5 portrays a high co-occurrence between KPls and elements in the disruption phase, following the pre-disruption phase, and lastly post-disruption. From this result, it can be reaffirmed that the non-financial $\mathrm{KPls}$ in this study are able to positively influence resilience more in the moment of the disruption instead of before or after it. Therefore, there is a lack of attention from the KPls to monitor certain actions in order to prepare the supply chain or deal with unexpected events by means of resource management.

As important as in the pre-disruption phase, knowledge management is also required in during- and post-disruption phases, recognizing that all knowledge must be recorded to be further used to mitigate and excel any type of disruptions. Consequently, information sharing, collaboration and visibility are also elements that must be developed as it is the basis for enhancing knowledge management. Although no clear evidence was identified in the literature about the correlation of all KPls for knowledge management element, it was observed that monitoring and managing all supply chain KPls is a source of information to improve knowledge management. It is especially notable in the post-disruption phase as the knowledge can be used to create or enhance other elements, such as security, flexibility and risk management. 
Finally, although there is much on the literature about the importance of visibility within the company and throughout the supply chain (Aragão et al., 2004; Chae, 2009; Anand \& Grover, 2015; Hohenstein et al., 2015; Ali et al., 2017), no clear co-occurrence between this element and specific KPls was found in the three phases of disruption; yet authors mentioned the creation of visibility through monitoring a set of KPls. In addition to this, no co-occurrence was also identified between financial health (element) to any non-financial KPI (nor specific, neither generic). Although this is a common cited element by SCRes authors, we assumed that it may be certainly linked to financial KPls instead of non-financial ones, as it requires or measures capital investment (from focal firm or suppliers) to be built.

\section{Conclusion}

This paper shed light on an underexplored topic which explores the influence of specific non-financial KPls in generating SCRes. As a first step in exploring this, a systematic literature review was conducted and analysis showed a positive influence between non-financial $10 \mathrm{KPls}$ and 11 elements of resilience (Table 5). Out of 13 elements of resilience identified, visibility and financial health did not present clear co-occurrence with the KPls discussed. Order and delivery lead time, stock level and customer satisfaction were the indicators that most co-occurred for the elements that support resilience. Notwithstanding, customer satisfaction was found to be a result of the management of other KPls so as to achieve SCRes. Among all elements, knowledge management presented the highest co-occurrence with the KPls (as in pre- or post-disruption), considering it is the source of knowledge to develop other elements.

This study contributes to the theory by raising elements of resilience and non-financial KPls from a fragmented literature, and connecting them in order to explore the use of KPIs in building SCRes. To practice, it can assist managers by identifying specific KPls that can help not only monitor the operations but also assist in the creation of organizational or supply chain resilience.

As every piece of research, it has a number of limitations. First, it is purely based on the body of knowledge presented in three databases over the past 17 years. Second, considering that the snowball search was not applied in this study, it might be interesting to check if it would identify additional relevant articles to improve the results. Third, articles in Portuguese were included in the systematic review, which may limit foreign researchers to replicate the present SLR process. However, we opted to include articles in Portuguese considering these findings will be validated through an empirical study in the Brazilian supply chains. The Brazilian context was chosen due to the increasing number of disruptive events that the entire country is facing and the lack of studies in resilience in the context. Future opportunities for research should evolve the purpose of this study by involving financial KPls or even the impact of the operational KPls in the financial KPls by creating SCRes.

\section{Acknowledgements}

The authors are grateful to the financial support granted by FAPESC (Santa Catarina Research Foundation) through the processes 2017TR759.

\section{References}

Ali, A., Mahfouz, A., \& Arisha, A. (2017). Analysing supply chain resilience: integrating the constructs in a concept mapping framework via a systematic literature review. Supply Chain Management, 22(1), 16-39. http://dx.doi.org/10.1108/SCM-06-2016-0197.

Ambulkar, S., Blackhurst, J., \& Grawe, S. (2015). Firm's resilience to supply chain disruptions: scale development and empirical examination. Journal of Operations Management, 33, 111-122. http://dx.doi.org/10.1016/j.jom.2014.11.002.

Anand, N., \& Grover, N. (2015). Measuring retail supply chain performance: theoretical model using key performance indicators (KPls). Benchmarking, 22(1), 135-166. http://dx.doi.org/10.1108/BlJ-05-2012-0034.

Aragão, A. B. D., Scavarda, L. F., Hamacher, S., \& Pires, S. R. 1. (2004). Supply chain management analysis model: fundaments and application to NVG cylinder chains. Gestão \& Produção, 11(3), 299-311. http://dx.doi.org/10.1590/S0104-530X2004000300005.

Asgari, N., Nikbakhsh, E., Hill, A., \& Farahani, R. Z. (2016). Supply chain management 1982-2015: a review. IMA Journal of Management Mathematics, 273), 353-379. http://dx.doi.org/10.1093/imaman/dpw004.

Avelar-Sosa, L., García-Alcaraz, J. L., \& Castrellón-Torres, J. P. (2014). The effects of some risk factors in the supply chains performance: a case of study. Journal of Applied Research and Technology, 12(5), 958-968. http://dx.doi.org/10.1016/S1665-6423(14)70602-9.

Bai, C., \& Sarkis, J. (2014). Determining and applying sustainable supplier key performance indicators. Supply Chain Management, 19(3), 275-291. http://dx.doi.org/10.1108/SCM-12-2013-0441.

Bardin, L. (2008). Análise de conteúdo. Lisboa: Edições 70.

Bhagwat, R., \& Sharma, M. K. (2007). Performance measurement of supply chain management: a balanced scorecard approach. Computers \& Industrial Engineering, 53(1), 43-62. http://dx.doi.org/10.1016/j.cie.2007.04.001. 
Blackhurst, J., Dunn, K. S., \& Craighead, C. W. (2011). An empirically derived framework of global supply resiliency. Journal of Business Logistics, 32(4), 374-391. http://dx.doi.org/10.1111/j.0000-0000.2011.01032.x.

Blaikie, N. W. H. (2010). Designing social research: the logic of anticipation. Cambridge: Polity Press.

Boyes, H. (2015). Cybersecurity and cyber-resilient supply chains. Technology Innovation Management Review, 5(4), 28-34. http:// dx.doi.org/10.22215/timreview/888.

Brandon-Jones, E., Squire, B., Autry, C. W., \& Petersen, K. J. (2014). A contingent resource $\square$ based perspective of supply chain resilience and robustness. The Journal of Supply Chain Management, 50(3), 55-73. http://dx.doi.org/10.1111/jscm.12050.

Brusset, X., \& Teller, C. (2017). Supply chain capabilities, risks, and resilience. International Journal of Production Economics, 184, 59-68. http://dx.doi.org/10.1016/j.jpe.2016.09.008.

Cai, J., Liu, X., Xiao, Z., \& Liu, J. (2009). Improving supply chain performance management: a systematic approach to analyzing iterative KPI accomplishment. Decision Support Systems, 46(2), 512-521. http://dx.doi.org/10.1016/j.dss.2008.09.004.

Carvalho, H., Barroso, A. P., Machado, V. H., Azevedo, S., \& Cruz-Machado, V. (2012). Supply chain redesign for resilience using simulation. Computers \& Industrial Engineering, 62(1), 329-341. http://dx.doi.org/10.1016/j.cie.2011.10.003.

Cedillo-Campos, M. G., Pérez-Salas, G., Bueno-Solano, A., González-Ramírez, R. G., \& Jímenez-Sánchez, E. (2014). Supply chain disruptions propagation caused by criminal acts. Journal of Applied Research and Technology, 12(4), 684-694. http://dx.doi. org/10.1016/S1665-6423(14)70085-9.

Chae, B. (2009). Developing key performance indicators for supply chain: an industry perspective. Supply Chain Management, 14(6), 422-428. http://dx.doi.org/10.1108/13598540910995192.

Chan, F. T. (2003). Performance measurement in a supply chain. International Journal of Advanced Manufacturing Technology, 21(7), 534-548. http://dx.doi.org/10.1007/s001700300063.

Chelariu, C., Kwame Asare, A., \& Brashear-Alejandro, T. (2014). “A ROSE, by any other name”...: relationship typology and performance measurement in supply chains. Journal of Business and lndustrial Marketing, 29(4), 332-343. http://dx.doi.org/10.1108/JBIM-082013-0178.

Cho, D. W., Lee, Y. H., Ahn, S. H., \& Hwang, M. K. (2012). A framework for measuring the performance of service supply chain management. Computers \& Industrial Engineering, 62(3), 801-818. http://dx.doi.org/10.1016/j.cie.2011.11.014.

Christopher, M. (2012). Logística e gerenciamento da cadeia de suprimentos: criando redes que agregam valor. São Paulo: Cengage Learning.

Christopher, M., \& Peck, H. (2004). Building the resilient supply chain. International Journal of Logistics Management, 15(2), 1-14. http://dx.doi.org/10.1108/09574090410700275.

Colicchia, C., \& Strozzi, F. (2012). Supply Chain risk management: a new methodology for a systematic literature review. Supply Chain Management, 17(4), 403-418. http://dx.doi.org/10.1108/13598541211246558.

Conceição, S. V., \& Quintão, R. T. (2004). Avaliação do desempenho logístico da cadeia brasileira de suprimentos de refrigerantes. Gestão \& Produção, 11(3), 441-453. http://dx.doi.org/10.1590/S0104-530X2004000300015.

De Felice, F., \& Petrillo, A. (2015). Multidimensional balanced efficiency decision model. Journal of Technology Management \& Innovation, 10(3), 92-103. http://dx.doi.org/10.4067/S0718-27242015000300011.

Denyer, D., \& Tranfield, D. (2009). Producing a systematic review. In D. A. Buchanan \& A. Bryman (Eds.), The Sage handbook of organizational research methods (pp. 671-689). London: Sage Publications.

Federal Emergency Management Agency - FEMA. (2016). Ready Business: QuakeSmart Toolkit. Washington: FEMA. Retrieved in 2018, March 16, from https://www.fema.gov/media-library-data/1510690321803-1e6c4874b251c3022ac4b57b0369e2da/QuakeSmart_ Ready_Business_Toolkit_Interactive_Final_508.pdf

Fernandes, R., Gouveia, J. B., \& Pinho, C. (2011). Medição da incerteza da procura numa cadeia de abastecimento com múltiplos pontos de inventário. Revista de Gestão dos Países de Língua Portuguesa, 10(4), 67-79. Retrieved in 2018, March 16, from http://www. scielo.mec.pt/scielo.php?pid=S1645-44642011000300007\&script=sci_arttext\&tlng=pt

Ferreira, F. A. L., Scavarda, L. F., Ceryno, P. S., \& Leiras, A. (2018). Supply chain risk analysis: a shipbuilding industry case. International Journal of Logistics Research and Applications, 21(5), 542-556. http://dx.doi.org/10.1080/13675567.2018.1472748.

Funo, K. A., Muniz r, J., \& Marins, F. A. S. (2013). Fatores de risco em cadeia de suprimentos do setor aeroespacial: aspectos qualitativos e quantitativos. Revista Produção, 23(4), 832-845. http://dx.doi.org/10.1590/S0103-65132013005000016.

Ganga, G. M. D., Carpinetti, L. C. R., \& Politano, P. R. (2011). Gestão do desempenho em cadeias de suprimentos usando lógica fuzzy. Gestão \& Produção, 18(4), 755-774. http://dx.doi.org/10.1590/S0104-530X2011000400006.

Ghalayini, A. M., \& Noble, J. S. (1996). The changing basis of performance measurement. International Journal of Operations \& Production Management, 16(8), 63-80. http://dx.doi.org/10.1108/01443579610125787.

Gunasekaran, A., Irani, Z., Choy, K. L., Filippi, L., \& Papadopoulos, T. (2015). Performance measures and metrics in outsourcing decisions: a review for research and applications. International Journal of Production Economics, 161, 153-166. http://dx.doi.org/10.1016/j. ijpe.2014.12.021.

Gunasekaran, A., Patel, C., \& McGaughey, R. E. (2004). A framework for supply chain performance measurement. International Journal of Production Economics, 8オ(3), 333-347. http://dx.doi.org/10.1016/j.ijpe.2003.08.003.

Gunasekaran, A., Patel, C., \& Tirtiroglu, E. (2001). Performance measures and metrics in a supply chain environment. International Journal of Operations \& Production Management, 21(1-2), 71-87. http://dx.doi.org/10.1108/01443570110358468.

Hohenstein, N. O., Feisel, E., Hartmann, E., \& Giunipero, L. (2015). Research on the phenomenon of supply chain resilience: a systematic review and paths for further investigation. International Journal of Physical Distribution \& Logistics Management, 45(1-2), 90-117. http://dx.doi.org/10.1108/1JPDLM-05-2013-0128.

Huang, S. H., \& Keskar, H. (2007). Comprehensive and configurable metrics for supplier selection. International Journal of Production Economics, 105(2), 510-523. http://dx.doi.org/10.1016/j.ijpe.2006.04.020.

Ivanov, D., Dolgui, A., Sokolov, B., \& Ivanova, M. (2016). Disruptions in supply chains and recovery policies: state-of-the art review. IFAC-PapersOnLine, 49(12), 1436-1441. http://dx.doi.org/10.1016/j.ifacol.2016.07.773. 
Jalali, S., \& Wohlin, C. (2012). Systematic literature studies: database searches vs. backward snowballing. In Proceedings of the International Conference on Empirical Software Engineering and Measurement. Sweden: Blekinge Institute of Technology. Retrieved in 2018, March 16, from http://www.wohlin.eu/esem12a.pdf

Jesson, J. K., Matheson, L., \& Lacey, F. M. (2011). Doing your literature review traditional and systematic techniques. Singapore: Sage Publications.

Jüttner, U., \& Maklan, S. (2011). Supply chain resilience in the global financial crisis: an empirical study. Supply Chain Management, 16(4), 246-259. http://dx.doi.org/10.1108/13598541111139062.

Kamalahmadi, M., \& Parast, M. M. (2016). A review of the literature on the principles of enterprise and supply chain resilience: major findings and directions for future research. International Journal of Production Economics, 171, 116-133. http://dx.doi.org/10.1016/j. ijpe.2015.10.023.

Kamalahmadi, M., \& Parast, M. M. (2017). An assessment of supply chain disruption mitigation strategies. International Journal of Production Economics, 184, 210-230. http://dx.doi.org/10.1016/j.jpe.2016.12.011.

Katiyar, R., Barua, M. K., \& Meena, P. L. (2015). Modelling the measures of supply chain performance in the lndian automotive industry. Benchmarking, 22(4), 665-696. http://dx.doi.org/10.1108/BlJ-09-2014-0091.

Khan, O., Christopher, M., \& Creazza, A. (2012). Aligning product design with the supply chain: a case study. Supply Chain Management, 17(3), 323-336. http://dx.doi.org/10.1108/13598541211227144.

Kuckartz, U. (1999). Computergestützte analyse qualitativer daten: eine einführung in die methoden und arbeitstechniken. Opladen: Westdeutscher Verlag. http://dx.doi.org/10.1007/978-3-322-86592-2.

Lam, J. S. L., \& Bai, X. (2016). A quality function deployment approach to improve maritime supply chain resilience. Transportation Research Part E, Logistics and Transportation Review, 92, 16-27. http://dx.doi.org/10.1016/j.tre.2016.01.012.

Lima, F. R. P., Silva, A. L., Godinho Filho, M., \& Dias, E. M. (2018). Systematic review: resilience enablers to combat counterfeit medicines. Supply Chain Management, 12(3), 117-135. http://dx.doi.org/10.1108/SCM-04-2017-0155.

Linnenluecke, M. K. (2017). Resilience in business and management research: a review of influential publications and a research agenda. International Journal of Management Reviews, 19(1), 4-30. http://dx.doi.org/10.1111/ijmr.12076.

Maestrini, V., Luzzini, D., Maccarrone, P., \& Caniato, F. (2017). Supply chain performance measurement systems: a systematic review and research agenda. International Journal of Production Economics, 183, 299-315. http://dx.doi.org/10.1016/j.jpe.2016.11.005.

Morini, C., Inácio Júnior, E., Santa-Eulália, L. A., \& Serafim, M. P. (2015). Indicadores de desempenho da Aduana do Brasil: em busca de uma abordagem equilibrada. Gestão \& Produção, 22(3), 508-524. http://dx.doi.org/10.1590/0104-530X1407-14.

Nagyova, A., \& Pacaiova, H. (2009). How to build manual for key performance indicators - KPl. In B. Katalinic (Ed.), DAAAM International Scientific Book (pp. 135-143). Vienna: DAAAM International. http://dx.doi.org/10.2507/daaam.scibook.2009.15.

Nudurupati, S. S., Bititci, U. S., Kumar, V., \& Chan, F. T. S. (2011). State of the art literature review on performance measurement. Computers \& Industrial Engineering, 60(2), 279-290. http://dx.doi.org/10.1016/j.cie.2010.11.010.

Oke, A., \& Gopalakrishnan, M. (2009). Managing disruptions in supply chains: a case study of a retail supply chain. International Journal of Production Economics, 118(1), 168-174. http://dx.doi.org/10.1016/j.jpe.2008.08.045.

Peng, M., Peng, Y., \& Chen, H. (2014). Post-seismic supply chain risk management: a system dynamics disruption analysis approach for inventory and logistics planning. Computers \& Operations Research, 42, 14-24. http://dx.doi.org/10.1016/j.cor.2013.03.003.

Pereira, C. R., Christopher, M., \& Lago Da Silva, A. (2014). Achieving supply chain resilience: the role of procurement. Supply Chain Management, 19(5/6), 626-642. http://dx.doi.org/10.1108/SCM-09-2013-0346.

Pereira, J. V. (2009). The new supply chain's frontier: information management. International Journal of Information Management, 29(5), 372-379. http://dx.doi.org/10.1016/j.jinfomgt.2009.02.001.

Pettit, T. J., Croxton, K. L., \& Fiksel, J. (2013). Ensuring supply chain resilience: development and implementation of an assessment tool. Journal of Business Logistics, 34(1), 46-76. http://dx.doi.org/10.1111/jbl.12009.

Ponomarov, S. Y., \& Holcomb, M. C. (2009). Understanding the concept of supply chain resilience. International Journal of Logistics Management, 20(1), 124-143. http://dx.doi.org/10.1108/09574090910954873.

Rajesh, R. (2016). Forecasting supply chain resilience performance using grey prediction. Electronic Commerce Research and Applications, 20, 42-58. http://dx.doi.org/10.1016/j.elerap.2016.09.006.

Rajesh, R., \& Ravi, V. (2015). Supplier selection in resilient supply chains: a grey relational analysis approach. Journal of Cleaner Production, 86, 343-359. http://dx.doi.org/10.1016/j.jclepro.2014.08.054.

Sacomano Neto, M., \& Pires, S. R. 1. (2012). Medição de desempenho em cadeias de suprimentos: um estudo na indústria automobilística. Gestão \& Produção, 19(4), 733-746. http://dx.doi.org/10.1590/S0104-530X2012000400006.

Sahu, A. K., Datta, S., \& Mahapatra, S. S. (2017). Evaluation of performance index in resilient supply chain: a fuzzy-based approach. Benchmarking, 24(1), 118-142. http://dx.doi.org/10.1108/BlJ-07-2015-0068.

Scavarda, L. F., Ceryno, P. S., Pires, S., \& Klingebiel, K. (2015). Supply chain resilience analysis: a Brazilian automotive case. Revista de Administração de Empresas, 55(3), 304-313. http://dx.doi.org/10.1590/S0034-759020150306.

Scholten, K., \& Schilder, S. (2015). The role of collaboration in supply chain resilience. Supply Chain Management, 20(4), 471-484. http://dx.doi.org/10.1108/SCM-11-2014-0386.

Scholten, K., Sharkey Scott, P., \& Fynes, B. (2014). Mitigation processes-antecedents for building supply chain resilience. Supply Chain Management, 19(2), 211-228. http://dx.doi.org/10.1108/SCM-06-2013-0191.

Sellitto, M. A., \& Mendes, L. W. (2006). Avaliação comparativa do desempenho de três cadeias de suprimentos em manufatura. Revista Produção, 16(3), 552-568. http://dx.doi.org/10.1590/S0103-65132006000300015.

Seuring, S., \& Gold, S. (2012). Conducting content-analysis based literature reviews in supply chain management. Supply Chain Management, 17(5), 544-555. http://dx.doi.org/10.1108/13598541211258609. 
Sjøbakk, B., Bakås, 0., Bondarenko, 0., \& Kamran, T. (2015). Designing a performance measurement system to support materials management in engineer-to-order: a case study. Advances in Manufacturing, 3(2), 111-122. http://dx.doi.org/10.1007/s40436015-0109-2.

Soni, U., Jain, V., \& Kumar, S. (2014). Measuring supply chain resilience using a deterministic modeling approach. Computers \& Industrial Engineering, 74, 11-25. http://dx.doi.org/10.1016/j.cie.2014.04.019.

Talluri, S. S., Kull, T. J., Yildiz, H., \& Yoon, J. (2013). Assessing the efficiency of risk mitigation strategies in supply chains. Journal of Business Logistics, 34(4), 253-269. http://dx.doi.org/10.1111/jbl.12025.

Thomé, A. M. T., Scavarda, L. F., \& Scavarda, A. J. (2016). Conducting systematic literature review in operations management. Production Planning \& Control, 27(5), 408-420. http://dx.doi.org/10.1080/09537287.2015.1129464.

Thomé, A. M. T., Scavarda, L. F., Fernandez, N. S., \& Scavarda, A. J. (2012). Sales and operations planning: a research synthesis. International Journal of Production Economics, 138(1), 1-13. http://dx.doi.org/10.1016/j.jpe.2011.11.027.

Tranfield, D., Denyer, D., \& Smart, P. (2003). Towards a methodology for developing evidence-informed management knowledge by means of systematic review. British Journal of Management, 14(3), 207-222. http://dx.doi.org/10.1111/1467-8551.00375.

Tranfield, D., Denyer, D., Marcos, J., \& Burr, M. (2004). Co-producing management knowledge. Management Decision, 42(3-4), 375386. http://dx.doi.org/10.1108/00251740410518895.

Urciuoli, L., Mohanty, S., Hintsa, J., \& Gerine Boekesteijn, E. (2014). The resilience of energy supply chains: a multiple case study approach on oil and gas supply chains to Europe. Supply Chain Management, 19(1), 46-63. http://dx.doi.org/10.1108/SCM-09-2012-0307.

Wang, X., Herty, M., \& Zhao, L. (2016). Contingent rerouting for enhancing supply chain resilience from supplier behavior perspective. International Transactions in Operational Research, 23(4), 775-796. http://dx.doi.org/10.1111/itor.12151.

Williams, Z., Ponder, N., \& Autry, C. W. (2009). Supply chain security culture: measure development and validation. International Journal of Logistics Management, 20(2), 243-260. http://dx.doi.org/10.1108/09574090910981323.

World Economic Forum. (2017). The Global Risks Report 2017 (12th ed.). Geneva: World Economic Forum. Retrieved in 2018, March 16, from http://www3.weforum.org/docs/GRR17_Report_web.pdf

Zhu, J., \& Ruth, M. (2013). Exploring the resilience of industrial ecosystems. Journal of Environmental Management, 122, 65-75. http:// dx.doi.org/10.1016/j.jenvman.2013.02.052. PMid:23562949. 